\title{
Study on the Quantitative Relationship Among Canopy Hyperspectral Reflectance, Vegetation Index and Cotton Leaf Nitrogen Content
}

\author{
Caixia Yin ${ }^{1}$ (D) Jiao $\operatorname{Lin}^{1} \cdot$ Lulu Ma $^{1} \cdot$ Ze Zhang $^{1} \cdot$ Tongyu Hou $^{1} \cdot$ Lifu Zhang $^{1,2} \cdot$ Xin $^{1}{ }^{1}$
}

Received: 5 June 2020 / Accepted: 10 March 2021 / Published online: 2 April 2021

(C) The Author(s) 2021

\begin{abstract}
Study the response mechanism of Canopy spectral reflectance (CSR) to cotton nitrogen fertilizer, propose the sensitive band and center wavelength of cotton leaf nitrogen content (LNC), and compare the response characteristics of various vegetation indexes to LNC, propose a vegetation index that responds well to LNC and construct estimating model. This experiment sets five nitrogen fertilizer levels, namely $\mathrm{N}_{0}$ (control), $\mathrm{N}_{120}\left(120 \mathrm{~kg} / \mathrm{hm}^{2}\right), \mathrm{N}_{240}\left(240 \mathrm{~kg} / \mathrm{hm}^{2}\right), \mathrm{N}_{360}(360 \mathrm{~kg} /$ $\left.\mathrm{hm}^{2}\right), \mathrm{N}_{480}\left(480 \mathrm{~kg} / \mathrm{hm}^{2}\right)$. Among them, referring to the conventional nitrogen fertilizer is applied by local farmers $\left(\mathrm{N}_{330}\right.$, $330 \mathrm{~kg} / \mathrm{hm}^{2}$ ). The results showed the following: (1) Visible light and near-infrared (NIR) can be used as two large ranges for precise monitoring of nitrogen, especially the CSR in the NIR range differs significantly under different nitrogen fertilizers. In the early stage of cotton growth, the CSR decreased with the nitrogen application rate increase, in a suitable nitrogen environment $\left(360 \mathrm{~kg} / \mathrm{hm}^{2}\right)$, and beyond $\mathrm{N}_{360}$, vice versa. In the later growth period, the CSR increases with the increase in nitrogen fertilizer. This trend is most evident in the short-wave NIR regions;(2) the range of 690-709 nm, 717-753 nm, and 940-958, which can be remote sensed by the spectral reflectance when cotton is affected in poor or rich nitrogen. The center wavelength corresponding to the nitrogen-sensitive band, respectively, are $697 \mathrm{~nm}$, $735 \mathrm{~nm}, 953 \mathrm{~nm}$, the band width can maintain 5-15 nm, generally not more than $20 \mathrm{~nm}$;(3) compared with the ratio vegetation index, difference vegetation index, and normalized vegetation index, the combined vegetation index of more than two bands has a better effect on cotton LNC monitoring, of which the index $\left(\mathrm{R}_{560}-\mathrm{R}_{670}\right) /\left(\mathrm{R}_{560}+\mathrm{R}_{670}-\mathrm{R}_{450}\right)$, $\left(\mathrm{R}_{700}-1.7 \times \mathrm{R}_{670}+0.7 \times \mathrm{R}_{450}\right) /\left(\mathrm{R}_{700}+2.3 \times \mathrm{R}_{670}-1.3 \times \mathrm{R}_{450}\right)$ are significantly related to $\mathrm{LNC}$ in this papers, and the correlation coefficients can reach, respectively, $0.935^{*}$ and $0.936^{*}$. These findings help to estimate the model of LNC. The model is as follows: $Y=19.883 \times \mathrm{x}+42.285$, where $\mathrm{x}$ refers to the combined vegetation index $\left(\mathrm{R}_{700-}\right.$ $\left.-1.7 \times \mathrm{R}_{670}+0.7 \times \mathrm{R}_{450}\right) /\left(\mathrm{R}_{700}+2.3 \times \mathrm{R}_{670}-1.3 \times \mathrm{R}_{450}\right), Y$ is LNC, but the model accuracy will be affected in the crop different phenological stage, and the model has the highest monitoring accuracy during the bud period.
\end{abstract}

Keywords Cotton · Nitrogen $\cdot$ Hyperspectral $\cdot$ Vegetation index

Lifu Zhang

zhanglf@ radi.ac.cn

$\triangle$ Xin Lv

1xshz@126.com

1 College of Agriculture, Shihezi University, Shihezi 832003, Xinjiang, China

2 Institute of Remote Sensing and Digital Earth, Chinese Academy of Sciences, Beijing 100080, China

\section{Introduction}

Cotton is an important strategic material in China and one of the world's major crops, which is closely related to human life. Nitrogen, as an important factor in cotton growth, has a significant impact on the development of cotton organs. However, too much or too little nitrogen fertilizer in cotton will cause a series of problems such as slow growth and low yield (Read, 2005). Traditional crop nitrogen measurement methods usually rely on destructively obtaining plant samples from the field and conducting long-term hazardous chemical tests in the laboratory. Some relatively new technologies are based on 
obtaining leaf color information such as SPAD-502 (Follett, 1992; Peng, 1996), chlorophyll Fluorescence to monitor leaf $\mathrm{N}$ status and recommended fertilizer application (Malavolta, 2004; Jia, 2007). However, these techniques mainly obtain information values from the leaves on a single plant of vegetation. In contrast, remote sensing technology provides a new method for plant large-area monitoring, and has broad prospects in crop growth monitoring (Zhang, 2014), nutrition diagnosis, and yield estimation (Feng, 2006; Rorie, 2011). There have been many crops on the monitoring of nitrogen nutrition using spectral techniques, such as corn (Chen, 2010), wheat, tobacco (Jia, 2013), but the spectral information is redundant and there are many influencing factors (Fitzgerald, 2010). We can see that scholars have different results on the same crop (Xue, 2004; Nguyen, 2006). This indicates that the appropriate bands for monitoring leaf nitrogen nutrition may vary with crop types and test conditions (Ollinger, 2008). For cotton, only by quantifying the relationship between LNC and CSR, and clarifying the cotton's nitrogen sensitive band and vegetation index, can the rational use efficiency of cotton nitrogen fertilizer be improved and provide help for increasing cotton yield and protect the ecological environment (Russell, 2006). At the same time, the information of canopy variables is predominant to accurately monitor nitrogen content in cotton fields. Watt (2003) pointed out that proper nitrogen application will promote nutrient absorption and utilization. Therefore, in the different phenological stage of cotton, better nitrogen fertilizer management is essential for cotton (Zhang, 2000). Using canopy hyperspectral to establish nitrogen nutrition monitoring index for different crops. Roger (1984) pointed out that the spectral sensitivity band and spectral index of the elements of crops are clearly defined, which has a strong advantage in crop nutrition monitoring, and can facilitate the application of cotton nitrogen fertilizer (Luciano, 2011). Blacker (1996) found that the reflection spectrum near $550 \mathrm{~nm}$ can well distinguish the difference of different nitrogen treatments of corn, and then determine the region of corn nitrogen sensitive wavelength is $550-710 \mathrm{~nm}$. Wang (1993) proposed that $760-900 \mathrm{~nm}$, $630-660 \mathrm{~nm}$ and $530-560 \mathrm{~nm}$ are sensitive bands for diagnosing the nitrogen nutrition level of rice leaves. Stone (1996) pointed out the vegetation index of the combination of the two spectral bands at $671 \mathrm{~nm}$ and $780 \mathrm{~nm}$, which can estimate the total nitrogen concentration in wheat plants. Inoue (1998) shows that the normalized difference vegetation index (NDVI; $1100 \mathrm{~nm}, 660 \mathrm{~nm}$ ) can be used predict nitrogen accumulation in rice populations. Wang (2006) had shown that the ratio vegetation index (RVI; $810 \mathrm{~nm}$, $560 \mathrm{~nm}$ ) can better predict leaf nitrogen accumulation (LNA) per unit soil area of rice. From above, it is of great significance to clarify cotton's nitrogen sensitive band and index.

\section{Materials and Methods}

\section{Test Location}

The experiment was conducted in 2018 and 2019 at the SHIHEZI Headquarters in XIJIANG, China. The average annual temperature is between 6.5 and $7.2{ }^{\circ} \mathrm{C}$. Temperatures are low in the north and high in the south. The highest temperature in a year occurs in July, with an average temperature of $25.1-26.1{ }^{\circ} \mathrm{C}$, of which the northern region is higher than that of the southern region; the lowest temperature occurs in January, with an average temperature of -18.6 to $15.5^{\circ} \mathrm{C}$, of which south of the region. The annual precipitation is between 125.0 and $207.7 \mathrm{~mm}$. The sunshine is abundant, the annual sunshine hours are from 2721 to $2818 \mathrm{~h}$, and the average wind speed is $1.5 \mathrm{~m} / \mathrm{s}$. The winters are long and severely cold, and summers are short and hot. It is a typical temperate continental climate (Fig. 1).

\section{Experimental Design}

\section{The Data Involve Two Years, and Five N Rates, Described Below}

The two-year tested varieties were XINLUZAO 45 and XINLUZAO 53 (mainly cotton varieties in XINJIANG). The single-factor completely random block design was adopted. The experimental site was continuous cropping of cotton, with protection lines around. Five treatments $\mathrm{N}_{0}$ (control), $\mathrm{N}_{120}\left(120 \mathrm{~kg} / \mathrm{hm}^{2}\right), \mathrm{N}_{240}\left(240 \mathrm{~kg} / \mathrm{hm}^{2}\right), \mathrm{N}_{360}$ $\left(360 \mathrm{~kg} / \mathrm{hm}^{2}\right)$, and $\mathrm{N}_{480}\left(480 \mathrm{~kg} / \mathrm{hm}^{2}\right)$ were set (Table 1),

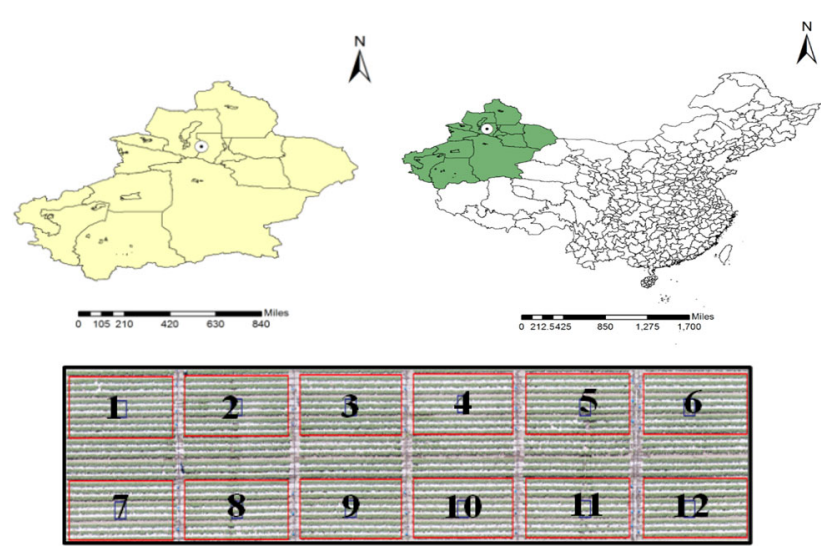

Fig. 1 Field diagram (the top left is a map of Xinjiang, The top right is a map of China, and the bottom is a cotton planting area) 
Table 1 Application amount of cotton Urea $(46 \% \mathrm{~N})$ in 2018 and 2019

\begin{tabular}{llllllll}
\hline Treatment & \multicolumn{1}{l}{ Top dressing $\left(\mathrm{kg} / \mathrm{hm}^{2}\right)$} \\
\hline $\begin{array}{l}\text { Year(2018) } \\
\text { Year(2019) }\end{array}$ & Data & $\begin{array}{r}\text { 13-June } \\
\text { 9-June }\end{array}$ & $\begin{array}{l}\text { 23-June } \\
\text { 19-June }\end{array}$ & $\begin{array}{l}\text { 14-July } \\
\text { 13-July }\end{array}$ & $\begin{array}{l}\text { 25-July } \\
\text { 22-July }\end{array}$ & $\begin{array}{l}\text { 5-August } \\
\text { 3-August }\end{array}$ & $\begin{array}{l}\text { 16-August } \\
\text { 12-August }\end{array}$ \\
\hline Treatment & BF (30\%) & Base fertilizer (70\%) & & & & \\
\hline $\mathrm{N}_{0}\left(0 \mathrm{~kg} / \mathrm{hm}^{2}\right)$ & 0 & 0 & 0 & 0 & 0 & 0 & 0 \\
$\mathrm{~N}_{120}\left(120 \mathrm{~kg} / \mathrm{hm}^{2}\right)$ & 78.26 & 20.87 & 20.87 & 26.09 & 31.30 & 39.13 & 44.35 \\
$\mathrm{~N}_{240}\left(240 \mathrm{~kg} / \mathrm{hm}^{2}\right)$ & 156.52 & 41.74 & 41.74 & 52.17 & 62.61 & 78.26 & 88.70 \\
$\mathrm{~N}_{360}\left(360 \mathrm{~kg} / \mathrm{hm}^{2}\right)$ & 234.78 & 62.61 & 62.61 & 78.26 & 93.91 & 117.39 & 133.04 \\
$\mathrm{~N}_{480}\left(480 \mathrm{~kg} / \mathrm{hm}^{2}\right)$ & 313.04 & 83.48 & 83.48 & 104.35 & 125 & 156.52 & 177.40 \\
\hline
\end{tabular}

each treatment is repeated 3 times, the area of each plot is $75 \mathrm{~m}^{2}(10 \mathrm{~m} * 2.5 \mathrm{~m} * 3)$, the film width is $2.05 \mathrm{~m}$, the line spacing is $10+66+10+66+10 \mathrm{~cm}$, and the plant spacing is $10.5 \mathrm{~cm}$. The drip was applied 7 times during the whole period, followed by the drip fertilizer 7 times, and the weight of drip fertilizer was set according to the fertilizer demand characteristics of cotton in different growth periods to determine the amount of nitrogen fertilizer applied each time. The CSR was acquired at each phenological stage and sampled to determine the LNC. Among them, BF means base fertilizer, which means applying fertilizer to the soil before planting cotton.

\section{Data Collection}

Acquisition of Spectral Data The CSR are obtained by the SR3500 produced by the American ASD company. Including visible light and near infrared range, the band range is $350-2500 \mathrm{~nm}$, and the resolution is $3 \mathrm{~nm}$. From 12:00 to 14:00 using Beijing time, choose sunny and cloudless weather measurements. Before starting the experiment, use a whiteboard to perform spectral calibration, and re-calibrate every $30 \mathrm{~min}$, the field of view angle is $25^{\circ}$, the average value of every ten spectrum is taken as a spectral value at this point, and each point is measured six times. Use the built-in software for averaging. The vegetation index is calculated using CSR.

Selection of Optimal Vegetation Index This paper selected 62 plantation indexes by consulting a large number of papers. (See appendix: Table 5). These indexes are divided into five categories, namely single band, ratio vegetation index, difference vegetation index, normalized vegetation index. The combined (more than two bands combined) index. Calculate the correlation coefficient between these indexes and LNC, select 16 indexes with better correlation with LNC, and then compare and analyze the indexes.
Determination of Nitrogen Content in Leaves During the four growth periods of cotton seedling stage (June 19), flourishing stage (July 5), boll stage (July 27), and flocking stage (August 27), each after measuring the spectral reflectance, the aerial parts of the plants were sampled, and the sample plants were divided into stems, leaves, buds, and bolls, killed at $105{ }^{\circ} \mathrm{C}$ for $30 \mathrm{~min}$, baked at $80{ }^{\circ} \mathrm{C}$ to constant weight, and weighed the dry weight of each part. Then the blade was crushed with a crusher, and the LNC was measured by K9840 meter produced by HANON Company in Shanghai, China.

\section{Statistical Analysis}

Using IBM SPSS Statistics 20 to analyze the correlation between LNC and CSR at different phenological stages, calculate the correlation coefficient (r) between every reflectance $(350-1000 \mathrm{~nm})$ and $\mathrm{LNC}$ at each crop growth period, using Origin make pictures in 2018, use linear stepwise regression equation to simulate the LNC. At the same time, In order to eliminate the dimensional influence between the cotton characteristic indexes, the CSR is standardized to solve the comparability between the data indexes. This paper uses the Mapminmax function to unify standardized reflectance. The map used by the Mapminmax function is as Eq. 1:

$y=\frac{(y \max -y \min ) *(x-x \min )}{(x \max -x \min )}+y \min$

In Eq. 1: xmin and xmax are the minimum and maximum values of the characteristic data set $\mathrm{x}$;

ymax and ymin are the range parameters of the mapping. In this experiment, $y \min =-1 * \operatorname{ymax}=1$ 


\section{Results}

\section{The Change Trend of LNC (Leaf Nitrogen Content), LW (Leaf Weight), LNA (Leaf Nitrogen Accumulation) at Different Phenological Stages}

Under the experimental conditions, in the $\mathrm{N}_{360}$ (fertilizer is $360 \mathrm{~kg} / \mathrm{hm}^{2}$ ) treatment, the LNC, leaf weight and the leaf nitrogen accumulation all reached relatively high level, and $\mathrm{N}_{0}$ (fertilizer is $0 \mathrm{~kg} / \mathrm{hm}^{2}$ ) is lower (Fig. 2a-f), Which can indicates only by applying suitable nitrogen fertilizer, can cotton accumulate nitrogen fertilizer in time when it needs nitrogen, Only that, cotton will show a better growth state, Therefore, The appropriate amount of nitrogen fertilizer is an important factor for cotton growth. At the same time, fertilizers cannot exceed cotton's own needing; otherwise it will inhibit cotton's absorption of nitrogen and increase unnecessary waste and environmental damage. In this experiment, $\mathrm{N}_{360}$ showed a better growth condition.

\section{Analysis of the Change Trend of Canopy Spectral Reflectance (CSR) of Cotton Under Nitrogen Stress}

From Fig. 3a-d, we can see that the change trend of the canopy spectral reflectance (CSR) of cotton in various phenological stages is similar to the trend of green vegetation. In the range of visible light and NIR region, the cotton CSR has significant differences on different nitrogen application rates. The CSR of the two wave ranges can be used effectively as a character area about the cotton LNC. Especially in the NIR region, the CSR is significantly
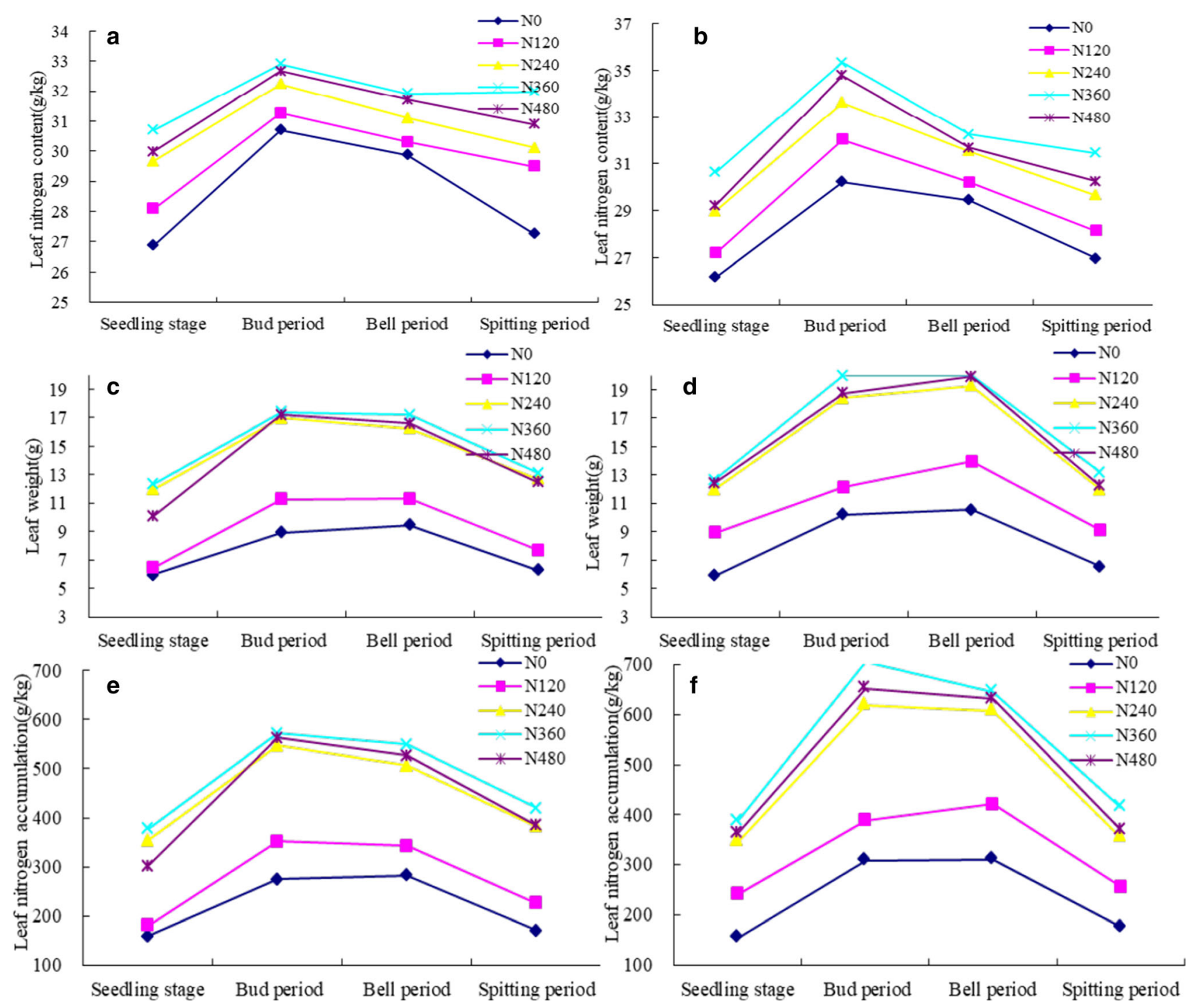

Fig. 2 a-f figure a,c,e are the value of LNC, leaf weight, leaf nitrogen accumulation in 2018, and figure b,d,f are the value of LNC, leaf weight and leaf nitrogen accumulation at different phenological stages in 2019. 
Fig. 3 a-d Change trend of Spectral Reflectance of Cotton Canopy in Various Periods
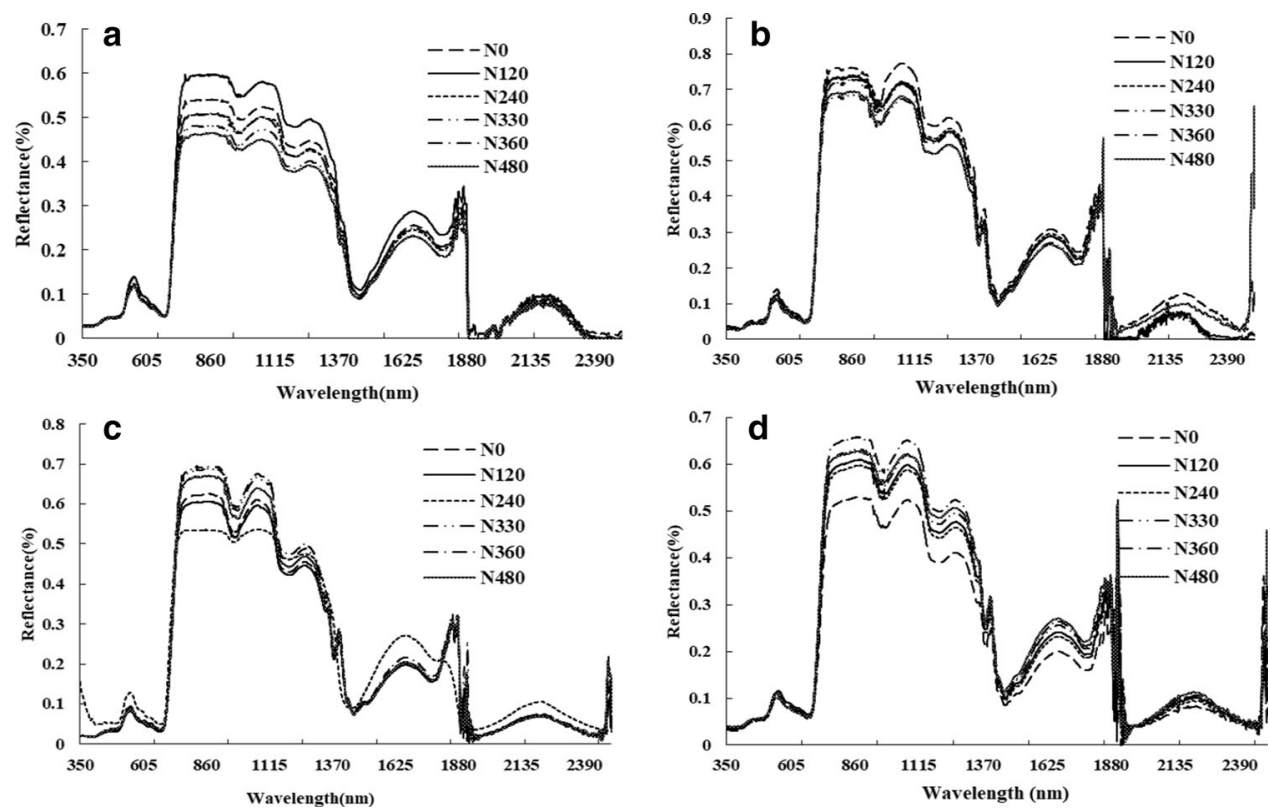

different under nitrogen stress, also has significant changes in different growth periods. The regular is changeless among different crops varieties. Among them, before July 6 (Bud stage period), in the NIR $(750-1350 \mathrm{~nm})$ region, the spectral reflectance of cotton canopy decreased with the increase in nitrogen. Within a suitable nitrogen application range, the CSR decreases with increasing nitrogen fertilizer. Under $\mathrm{N}_{330}\left(330 \mathrm{~kg} / \mathrm{hm}^{2}\right)$ treatment, the CSR showing the lowest trend, and in the $\mathrm{N}_{0}\left(0 \mathrm{~kg} / \mathrm{hm}^{2}\right)$ treatment, the CSR is the highest. When the nitrogen fertilizer exceeds cotton's demand $\left(\mathrm{N}_{480}, 480 \mathrm{~kg} / \mathrm{hm}^{2}\right)$, the CSR gradually increases with the increase of nitrogen fertilizer, this may be the nitrogen molecules absorb the solar radiation, but too many nitrogen molecules will weaken the ability to absorb solar radiation. But after the bud stage period, the regular about CSR with the nitrogen fertilizer increasing is significant different than above. Even trend is completely opposite to the before the Bud stage period. The above shows that CSR has a strong sensitivity to the growth period of cotton and nitrogen fertilizers. Among them, cotton mainly grows vegetative in the early stages of growth, and the effect of fertilizer demand is obvious, the less reflection. However, in the later stages of cotton growth, cotton mainly grows reproductively, and its fertilizer requirement decreases. The more nitrogen fertilizer, the more it is suppressed, resulting in reduced solar absorption and greater reflectivity.

The change trends of CSR with different LNC were observed, and we found that the spectral curve changes significantly under nitrogen stress. The two areas with the most obvious changes are the green peak and the near infrared. Therefore, we will focus on exploring the response characteristics of these two regions to nitrogen.
Because the nitrogen fertilizer treatment is relatively close, the tiny CSR difference caused by nitrogen fertilizer difference is not easy to be found. In order to more clearly explore the relationship between nitrogen and CSR, we roughly divided the nitrogen fertilizer into two treatments: poor nitrogen $\left(\mathrm{N}_{0}, 0 \mathrm{~kg} / \mathrm{hm}^{2}\right)$ and rich nitrogen $\left(\mathrm{N}_{480}\right.$, $480 \mathrm{~kg} / \mathrm{hm}^{2}$ ) and observed the change range of reflectance under the two treatments. The results showed that in the rich nitrogen and poor nitrogen treatments of cotton, the CSR changed significantly (Fig. 4a,b).

In the visible light region, the CSR changes were $24 \%$, $26 \%, 30 \%,-25 \%$, in the seedling, flowering, boll, and bollout periods, respectively, in 2018. using the CSR in 2019 to verify, it was found that the CSR changes were $16 \%, 22 \%$, $18 \%$, and $-5 \%$ during the seedling, flowering, boll, and spitting period, which can be seen that the level of nitrogen fertilizer can significantly affect the green peak region of CSR. The wavelength of the green peak area used in this experiment is $543-548 \mathrm{~nm}$. In the near-infrared region, the magnitude of CSR changes were $10 \%, 16 \%, 31 \%$, and $-12 \%$ in the seedling, flowering, boll, and spitting stages respectively, in 2018. using the CSR in 2019 to verify, we found that the CSR changes were $17 \%, 8 \%, 12 \%,-3 \%$ respectively, in the seedling, flowering stages, Boll period, and spitting period. In general, the change magnitude of CSR with different nitrogen treatment in the near-infrared region is smaller than that of visible light, but the magnitude of changes in the near-infrared region is also greater. Therefore, it is clear that the value of nitrogen fertilizer will cause significant changes in CSR in the visible and near infrared regions. In the early stage of cotton growth, CSR decreased significantly with the increase in nitrogen 


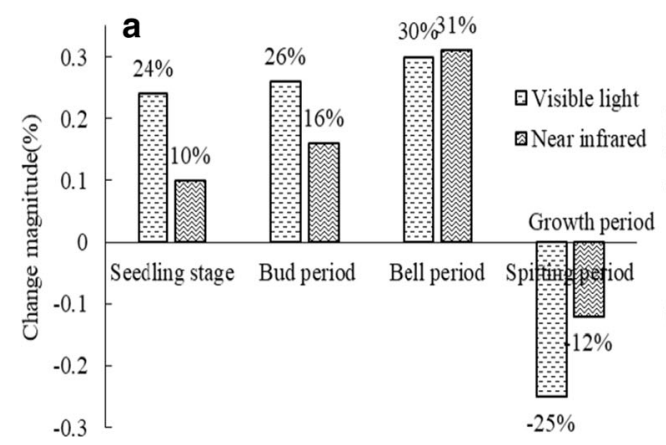

Fig. 4 a,b the magnitude of CSR changes with nitrogen in different periods. Note: a stands for the data in 2018. $b$ stands for the data in 2019. The nitrogen fertilizer and CSR show the opposite trend, The CSR decreases when nitrogen fertilizer increases. But after the boll

fertilizer, and at the later stage of growth, CSR also increased with the increase of nitrogen fertilizer.

The CSR analysis from different phenological stages shows (Fig. 5a,b) that the CSR in each period is not higher than $70 \%$. In the near-infrared region, after whiteboard calibration, the value of CSR is about 0.4 at the seedling stage, about 0.5 at the boll stage, about 0.6 at the boll stage, and 0.6 or more at the flowering stage, but overall it will not exceed $70 \%$. The change trend of cotton CSR is as follows: In the visible light region, the CSR trend is Seedling stage $>$ spitting stage $>$ Bell stage $>$ Bud stage, in the near-infrared region, the basic trend is Bud stage $>$ Bell stage $>$ spitting stage $>$ Seedling stage.

And at the position of the red edge, as the phenological period advances, the CSR of the red edge obviously shows a red shift. From the bud stage to the flower-bell stage, the CSR decreases in the visible range and rises in the nearinfrared band. The difference in CSR between cotton at the seedling stage and the boll stage was significant. From above, we can know that the CSR of different phenological stages has significant changes in visible light, near infrared and red edge positions. The changing regular is related to cotton LNC, leaf dry weight, and leaf nitrogen accumulation. That is, as these three increase, the near-infrared CSR decreases and the visible light reflectance increases, and

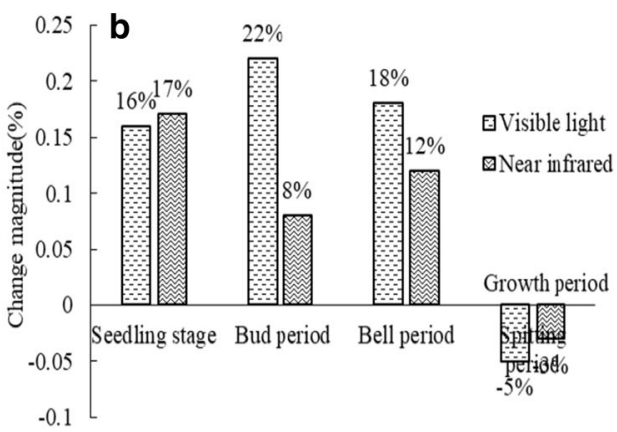

period of cotton growth, this trend is exactly opposite. Therefore, the change magnitude of CSR before the boll period is defined as a positive value, and the reflectance change range after the boll period is defined as a negative value

the red edge will show a red shift trend. This is also because different phenological stages caused the differences of the LNC, leaf dry weight, and leaf nitrogen accumulation. The corresponding characteristics of CSR to different phenological stages were demonstrated. In short, under different growth period, cotton CSR has obvious dynamic changes at different growth stages, which provides a basis for analyzing and establishing a quantitative relationship between the LNC of cotton and the CSR.

\section{Correlation Analysis of CSR (Canopy Spectral Reflectance) and LNC (Leaf Nitrogen Content), Select the Nitrogen Sensitive Band and Center Wavelength}

Three statistical methods are used to select the nitrogen sensitive band (The results are shown in Table 2). Among them, PCA analysis mainly eliminates the redundant information of the spectrum through spectral dimension reduction. Using spectral fitting algorithm, new fitted variables are used to replace the original complex band. In this paper, two principal component factors are selected, and each principal component factor are calculated to get a new variable combined with the proportion of principal component. According to the size of the new variable, there
Fig. 5 a,b Comparison of Spectral Reflectance of Cotton Canopy in Various Periods.

Note: a stands for the data in 2018. $b$ stands for the data in 2019
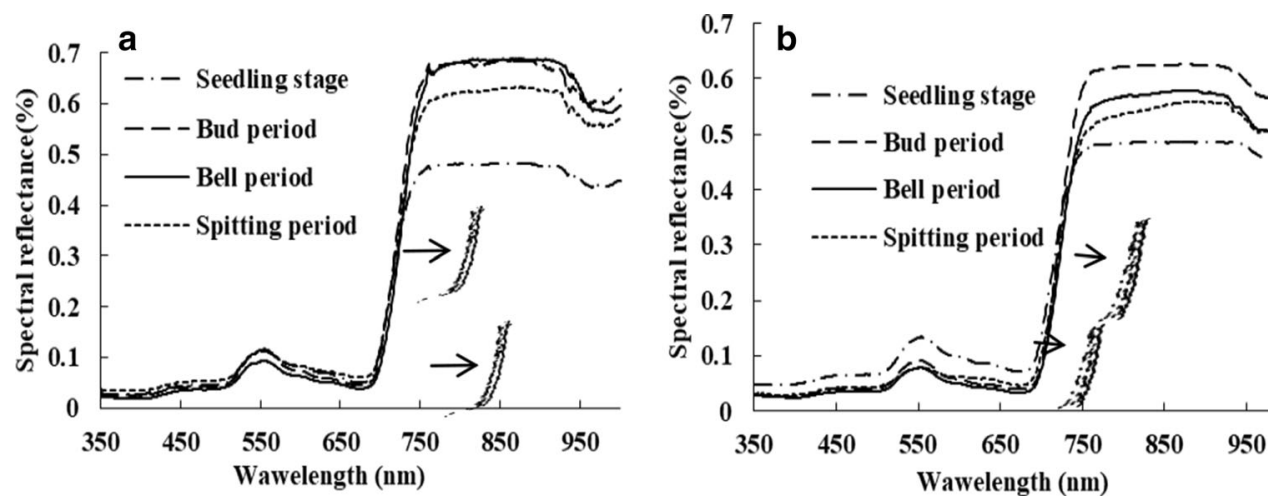
Table 2 Central wave of nitrogen proposed using different statistical and mathematical technique

\begin{tabular}{llcc}
\hline & Pearson coefficient & Covariance & PCA \\
\hline Center & $539 \mathrm{~nm}, 576 \mathrm{~nm}, 612 \mathrm{~nm}, 650 \mathrm{~nm}$ & $525 \mathrm{~nm}, 697 \mathrm{~nm}, 735 \mathrm{~nm}, 932 \mathrm{~nm}$, & $525 \mathrm{~nm}, 717 \mathrm{~nm}, 932 \mathrm{~nm}$ \\
wavelength & & $953 \mathrm{~nm}$ & $511-537 \mathrm{~nm}$, \\
Sensitive band & $504-553 \mathrm{~nm}, 560-596 \mathrm{~nm}$ & $515-535 \mathrm{~nm}, 687-711 \mathrm{~nm}$ & $690-753 \mathrm{~nm}$ \\
& $603-622 \mathrm{~nm}, 633-667 \mathrm{~nm}$ & $716-769 \mathrm{~nm}, 924-939 \mathrm{~nm}$ & $940-958 \mathrm{~nm}$ \\
& $685-709 \mathrm{~nm}, 717-756 \mathrm{~nm}$ & $943-958 \mathrm{~nm}, 986-1010 \mathrm{~nm}$ & \\
& $767-776 \mathrm{~nm}, 785-794 \mathrm{~nm}$ & & \\
& $992-1038 \mathrm{~nm}$ & & \\
\hline
\end{tabular}

are three bands are selected, respectively, 511-537 $\mathrm{nm}$, 690-753 nm, 940-958 nm. Then, using covariance and Pearson correlation coefficient, respectively, we determine the sensitive bands related to LNC. Among them, the bands chosen by Pearson correlation coefficients are complex, including $\quad 504-553 \mathrm{~nm}, \quad 560-596 \mathrm{~nm}, \quad 603-622 \mathrm{~nm}$, 633-667 nm, 685-709 nm, 717-756 nm, 767-776 nm, $785-794 \mathrm{~nm}, 992-1038 \mathrm{~nm}$. Using covariance value to determine the bands are $515-535 \mathrm{~nm}, 687-711 \mathrm{~nm}$, 716-769 nm, 924-939 nm, 943-958 nm, 986-1010 nm. We can conclude that the center wavelength and the sensitive band obtained by different statistical methods are some difference. Aiming at the nitrogen sensitive areas proposed by the predecessors, the range is 550-710 (Blacker, 1996), 760-900, 630-660, 530-560 (Wang 1993). This paper compares a variety of statistical methods. The four sensitive areas are proposed that, respectively, are 690-709 nm, 717-753 nm, and 940-958, where can be remote sensed by the spectrum when cotton is affected in poor or rich nitrogen. At the same time, we proposed the center wavelength corresponding to the nitrogen sensitive band; the significance about band width can maintain 5-15 nm, generally not more than $20 \mathrm{~nm}$. Combining these sensitive wave, then we use the Pearson correlation

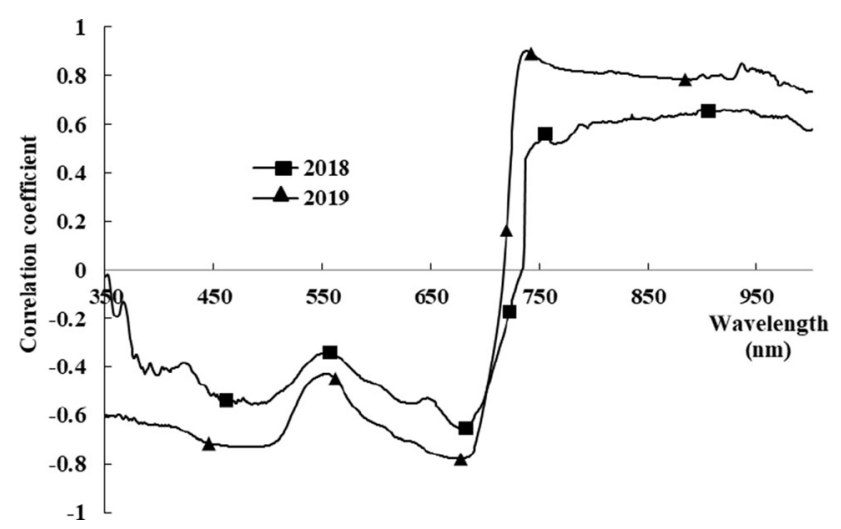

Fig. 6 The correlation coefficient between canopy spectral reflectance and $\mathrm{LNC}$ coefficient to focus on the correlation trend of each spectral sensitive area, as shown in Fig. 6.

At the same time, we analyze the correlation coefficients of the original CSR and LNC in 2018 and 2019 (Fig. 6), we can judge that the cotton CSR has obvious difference when cotton is in state of normal nitrogen or low nitrogen. So the CSR is suitable to monitor the cotton LNC. We separately collected 18 sets of the CSR and cotton LNC during cotton seedling, budding, boll, and spitting stages, and 72 sets of samples are adopted, and the Pearson correlation coefficient is used for detailed correlation analysis. The linear correlation analysis between the spectral reflectance of all bands(350-1000) and the LNC shows that LNC is negatively related to the single-band reflectivity in the visible light band (460-710 nm) and positively correlated to the near infrared short-wave band (760-1000 nm). Among them, the correlation coefficient between the spectral band and LNC in the 560-710 $\mathrm{nm}$ region can reach -0.88 and the correlation coefficient in the near infrared band can reach 0.60 . Therefore, these bands can be used as the main spectral bands indicating LNC in cotton. Using these main bands to construct spectral indicators, and a comprehensive regression analysis of $\mathrm{LNC}$ and spectral indicators, can be better used to monitor LNC. Compared with other spectral regions, the spectral reflectance has the best correlation with LNC in the red light region $(650-680 \mathrm{~nm})$, and this region is more suitable for monitoring LNC. The predecessors showed that the red light range is strong absorption band region about Chlorophyll. Due to the strong correlation between chlorophyll and nitrogen, nitrogen has a strong sensitivity around $680 \mathrm{~nm}$. This also confirms the views of the predecessors. At the seedling stage, the best band of nitrogen sensitivity in 2018 was $677-682 \mathrm{~nm}$, and the correlation coefficient was -0.777 . It is $681 \mathrm{~nm}$ in 2019, and the correlation coefficient is -0 . 929. At the same time, the data of other growth stages all show that the CSR has a good correlation with LNC. The LNC in the current bud stage has the highest correlation coefficient with CSR. Therefore, it may be better to estimate the nitrogen content of cotton leaves by CSR at the current bud 
stage than other growth stages. They have not reached a significant correlation, although LNC and CSR have a high correlation coefficient. Generally speaking, the trend of the correlation coefficient curve of the two year is the similar, but it can be seen that the correlation coefficient of CSR and LNC in the near infrared region in 2018 is not as high as in 2019. Therefore, we have consulted a large number of papers, and screened out the many vegetation indexes that can better monitor LNC from about 60 indices (Please see appendix, Table 5).

\section{Selection and Analysis of Nitrogen Sensitive Vegetation Index}

In this paper, through the 60 kinds of nitrogen sensitivity index displayed by the predecessors, test the correlation with the LNC, a total of 14 kinds of vegetation indexes with good correlation were selected (Table 3). From the table, we can see the single band, the ratio vegetation index, the difference vegetation index, and the normalized vegetation index all has a good correlation with cotton LNC. The correlation coefficient is between 0.50 and 0.90 , but after the correlation test, it is found that the response characteristics to the LNC have not reached a significant correlation. Compared with the ratio vegetation index, difference vegetation index, and normalized vegetation index, the combined vegetation index more than two bands has a better correlation with the LNC. The combined index with the lowest correlation coefficient is MTVI1: 1.2[1.2( $\left.\left.\mathrm{R}_{800}-\mathrm{R}_{550}\right)-2.5\left(\mathrm{R}_{670}-\mathrm{R}_{550}\right)\right]$, the coefficient can reach 0.891 , and the highest correlation coefficient is the index $\left(\mathrm{R}_{700}-1.7 \times \mathrm{R}_{670}+0.7 \times \mathrm{R}_{450}\right) / \quad\left(\mathrm{R}_{700}+2.3 \times\right.$ $\mathrm{R}_{670}-1.3 \times \mathrm{R}_{450}$ ), the coefficient can reach 0.936 , and all reached significant differences at 0 . 05 level. And the response characteristics of the combined index to LNC are not changed in different growth period.

\section{Nitrogen Monitoring Model Recommendation}

Using linear stepwise regression to construct the monitoring model (Table 4.), the data is divided into modeling set and verification set. Use the data in 2018 to build the estimation model, and use the data in 2019 to verify the model performance, the verification results are shown in Fig. 7. When constructing the model, 36 sample sizes were used in each period. The linear stepwise regression

Table 3 Selection of vegetation index

\begin{tabular}{|c|c|c|}
\hline Index & Formula & $\begin{array}{l}\text { Correlation } \\
\text { coefficient }\end{array}$ \\
\hline \multirow[t]{4}{*}{ Single band } & $\mathrm{R}_{416}$ & 0.59 \\
\hline & $\mathrm{R}_{543}$ & 0.72 \\
\hline & $\mathrm{R}_{589}$ & 0.61 \\
\hline & $\mathrm{R}_{616}$ & -0.67 \\
\hline \multirow[t]{4}{*}{ Ratio vegetation index } & $\mathrm{R}_{800} / \mathrm{R}_{635}$ & 0.734 \\
\hline & $\mathrm{R}_{780} / \mathrm{R}_{670}$ & 0.804 \\
\hline & $\mathrm{R}_{777} / \mathrm{R}_{759}$ & 0.799 \\
\hline & $\mathrm{R}_{810} / \mathrm{R}_{660}$ & 0.789 \\
\hline \multirow[t]{2}{*}{ Difference Vegetation Index } & $\mathrm{R}_{800}-\mathrm{R}_{670}$ & 0.818 \\
\hline & $\mathrm{R}_{800}-\mathrm{R}_{700}$ & 0.718 \\
\hline \multirow[t]{4}{*}{ Normalized vegetation index } & $\left(\mathrm{R}_{800}-\mathrm{R}_{680}\right) /\left(\mathrm{R}_{800}+\mathrm{R}_{680}\right)$ & 0.792 \\
\hline & $\left(\mathrm{R}_{750}-\mathrm{R}_{705}\right) /\left(\mathrm{R}_{750}+\mathrm{R}_{705}\right)$ & 0.742 \\
\hline & $\left(\mathrm{R}_{827}-\mathrm{R}_{668)}\right)\left(\mathrm{R}_{827}+\mathrm{R}_{668}\right)$ & 0.792 \\
\hline & $\left(\mathrm{R}_{800}-\mathrm{R}_{670}\right) /\left(\mathrm{R}_{800}+\mathrm{R}_{670}\right)$ & 0.793 \\
\hline \multirow{4}{*}{$\begin{array}{l}\text { Combined (more than two bands combined) } \\
\text { index }\end{array}$} & (1)TVI $=0.5\left[120 \times\left(\mathrm{R}_{750}-\mathrm{R}_{550}\right)-200 \times\left(\mathrm{R}_{670}-\mathrm{R}_{550}\right)\right]$ & $0.903^{*}$ \\
\hline & (2)MTVI1 $=1.2 \times\left[1.2 \times\left(\mathrm{R}_{800}-\mathrm{R}_{550}\right)-2.5 \times\left(\mathrm{R}_{670}-\mathrm{R}_{550}\right)\right]$ & $0.891^{*}$ \\
\hline & (3) VAGR $=\left(\mathrm{R}_{560}-\mathrm{R}_{670}\right) /\left(\mathrm{R}_{560}+\mathrm{R}_{670}-\mathrm{R}_{450}\right)$ & $0.935^{*}$ \\
\hline & $\begin{array}{l}\text { (4) VARI red }=\left(\mathrm{R}_{700}-1.7 \times \mathrm{R}_{670}+0.7 \times \mathrm{R}_{450}\right) /\left(\mathrm{R}_{700}+2.3 \times \mathrm{R}_{670^{-}} 1 .\right. \\
\left.3 \times \mathrm{R}_{450}\right)\end{array}$ & $0.936^{*}$ \\
\hline
\end{tabular}

*Refers to reaching a significant relationship at the 0.05 level,

${ }^{* *}$ Refers to reaching a significant relationship at the 0.01 level 
Table 4 Model recommendation

\begin{tabular}{lllll}
\hline Growth Period & Recommended model & $\mathrm{R}^{2}$ & RMSE & N-RMSE(\%) \\
\hline Seedling stage & $\mathrm{Y}=13.884 \times \mathrm{x}+42.513$ (x refers to index (2)) & 0.552 & 0.89 & 3.7 \\
Bud period & $\mathrm{Y}=19.883 \times \mathrm{x}+42.285$ (x refers to index(4) & 0.916 & 0.32 & 0.4 \\
Bell period & $\mathrm{Y}=14.237 \times \mathrm{x}+42.345$ (x refers to index (4) & 0.711 & 0.48 & 2.79 \\
Spitting period & $\mathrm{Y}=14.653 \times \mathrm{x}+41.982$ (x refers to index(3) & 0.696 & 0.73 & 1.27 \\
\hline
\end{tabular}

To facilitate the layout, The Combined (more than two bands combined) index has 4 pieces, Separate record (1),(2),(3),(4) (see Table 3) methods use the optimal index to estimate LNC. The results show that the model established in the bud period has the best performance, the representative model is $Y=19.883 \times \mathrm{x}+42.285$, the $\mathrm{R}^{2}$ can reach 0.916 .

Using 36 samples in 2019 for model verification, the results of the bud period verification set and the test set are similar, and $\mathrm{R}^{2}$ can reach 0.87 . It shows that the model is fit for estimating LNC, and the performance is not limited in the same phenological stage in different years. However, using other growth period data to verify, there are 72 samples in each growth period and 288 samples in four phenological stages. The results show that the model is very negative in estimating the $\mathrm{LNC}$, which showed that the using the CSR to estimate LNC needs to thinking changes in cotton spectrum and biochemical parameters at different growth stages. Applying the estimation model of one period to other period is not fit to estimate the LNC, the accuracy will significantly negative or even unusable. Therefore, considering these circumstances, the external influence factors should be considered when constructing the LNC model. The independent variables of the model should not only focus on the vegetation index, but also consider the vegetation differences in each growth period, or introduce coefficients, and convert factor when building models, which enables the model to be accurately applied in various periods (Fig. 7).

Simultaneously, the model can be constructed by dividing the growth period area, without interfering with each other, and the estimation accuracy of the LNC can be improved to achieve the purpose of leaf nitrogen estimation.

\section{Discussion}

This paper uses experimental data under different nitrogen treatments in 2018 and 2019, and comprehensively analyzes the relationship between the CSR and LNC, but we
Fig. 7 a-d Comparison of the model accuracy between test set (in 2018) and validation set (in 2019). Note: a-d represents four growth stages of cotton. Among them, a: seedling stage, $\mathbf{b}$ : bud period, $\mathbf{c}$ : bell period, $\mathbf{d}$ : spitting period
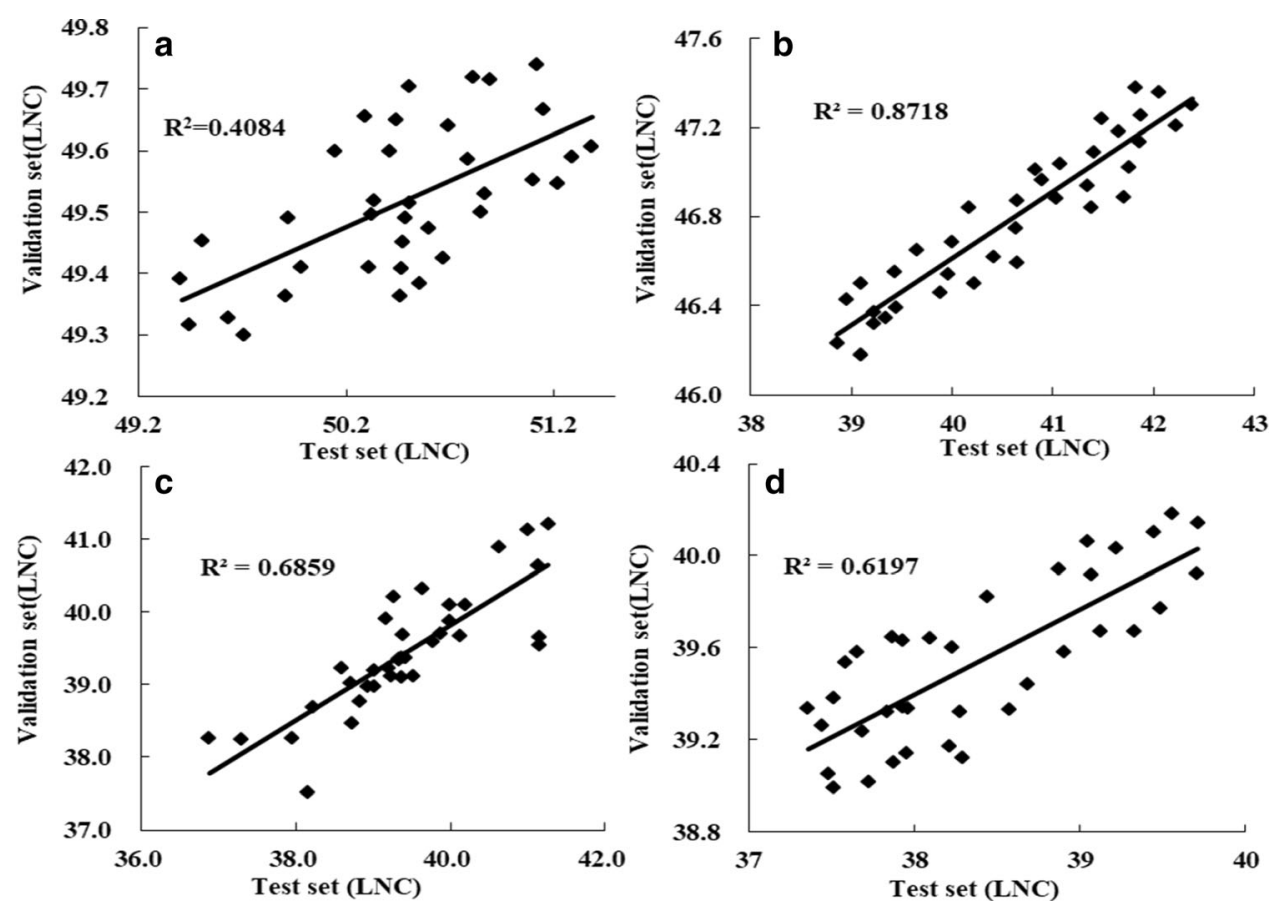
found that the effect was not so positive. They have not reached significant correlation, although LNC and CSR have a high correlation coefficient. Generally speaking, the trend of the correlation coefficient curve of the two year is the similar, but it can be seen that the correlation coefficient of CSR and LNC in the NIR in 2018 is not as high as in 2019. Nevertheless, experiments have found that some vegetation indices have a significant relationship with LNC. Nitrogen estimation model based on vegetation index has a better effect. However, there still have many factors to limit leaf nitrogen content monitoring based on spectroscopy technology, which will be discussed from the following aspects:

\section{Analysis of Influencing Factors of Nitrogen Monitoring by Spectrum}

Fully consider the interference factors of the monitoring model-cotton itself. The cotton CSR at different growth stages has a significant change. The monitoring of cotton LNC through spectral techniques has many limiting factors, such as weather, sunshine, detailed time and observation angle of acquiring CSR, parameters of the spectroscopic instrument itself. Regardless of the external environment, the monitoring process needs to fully consider the effects of growth period and fertilization. Regardless of the appearance or molecular changes, the growth rate of cotton is very fast, so we recommend building model in a more specific direction. For example, the monitoring model can be recommended in different period to improve the accuracy of model application.

At the same time, the spectral, especially hyperspectral data, because of its high spectral resolution, the information may include much material information from other materials, which may conceal the spectral changes brought by different nitrogen. Therefore, the preprocessing of spectral data is particularly important. In this experiment, even if a total of 108 sets of spectral information of all phenological stages of cotton were obtained, the spectral difference caused by the nitrogen difference could not be quickly identified. In this paper, the first derivative has a significant effect to correlation between the CSR and LNC. So when we explore the relationship between crop and spectrum in the future, one method about spectral pretreatment can be used to compare to find one better that can significantly identify nitrogen changes. Perhaps this will provide more convenience for the spectral detection of crops.

\section{The Effect of Vegetation Index on Crop Nitrogen Monitoring}

Different vegetation indices have different effects in the crop monitoring. When optimizing the vegetation index, the growth period should be considered, and the function of the vegetation index itself should be fully considered. The current results were obtained from an ecological area, despite several experiments conducted over 2 years in XIN JIANG. This means that the above cotton LNC sensitive index has certain reliability, In order to make the index more conducive to nitrogen monitoring; we should be further tested with independent data sets from different ecological regions and production systems, which will help to make them under a series of conditions more reliable and useful. In addition, the varieties used in this experiment are all upland cotton varieties; therefore, whether the results of this study are applicable to hybrid cotton varieties still needs further evaluation. This paper proposes that the combined vegetation index composed of three wavebands and above is more suitable for cotton nitrogen monitoring than the vegetation index fewer than two wavebands. The result is similar to the monitoring results of Stone (1996), which confirms the vegetation has a highest reliability about crop monitoring.

The construction of hyperspectral data contains numerous and unnecessary information. When we collect spectral information to complete scientific exploration, the number of spectral samples can significantly affect the test results. The selection of the number of spectral sample is related to the crop area. And cotton is one large-area crops in XIN JIANG. Therefore, the sample size must be geographically representative. The second is to carry out a variety of preprocessing on the data to eliminate some of the external environment's impact on the data itself, such as anti-noise and anti-interference from some environmental factors. When we constructing the model, the models constructed by different methods are very different. In order to improve the estimation accuracy of the model, we can combine the growth period and compare multiple construction methods. We recommend several commonly used methods, such as the popular deep learning in recent years; neural networks have strong advantages in the construction of some vegetation models.

\section{Conclusion}

In general, first of all, under various nitrogen fertilizer environments, the trend of CSR changes significantly, and the visible light can be used as a focus area for nitrogen fertilizer levels. Secondly, the nitrogen nutritional status of leaves is highly correlated with visible and near-infrared short-band spectral indicators. The combined vegetation index of more than two bands is better than other index, like normalized vegetation index, ratio vegetation index, difference vegetation index. Finally, there are many factors that can affect spectral reflectance, including cropgrowth environment, weather conditions, and the influence of the instrument itself. When 
monitoring crop nitrogen, it is necessary to minimize the errors caused by external factors. In this article, we use different statistical and mathematical technique to recommend several spectral waves that has better responses to cotton nitrogen monitoring. Then, we select the better vegetation index in these wave ranges. Through comparison, we propose several vegetation indices significantly related to cotton nitrogen. Based on these vegetation indices, we built nitrogen monitoring model. Therefore, this paper recommends cotton LNC monitoring model, the model is $Y=19.883 \times \mathrm{x}+42.285$, where $\mathrm{x}$ refers to the vegetation index: $\mathrm{R}_{700}-1.7 \times \mathrm{R}_{670}+$ $\left.0.7 \times \mathrm{R}_{450}\right) /\left(\mathrm{R}_{700}+2.3 \times \mathrm{R}_{670}-1.3 \times \mathrm{R}_{450}\right), Y$ is the leaf nitrogen content (LNC), the $\mathrm{R}^{2}$ can reach 0.877 . Also it is not affected by the cotton variety in different crop planting years, but the model is greatly restricted by the crop growth period, so when we building monitoring model, the crop growth period is an important factor that affects the accuracy of the model.

Acknowledgements This paper was supported and funded by the EXCELLENT project (funding from The Major Science and Technology Project of XINJIANG Production and Construction Corps, 2018AA004). Thanks for that. Simultaneously, Thanks to my tutors Professor ZHANG Li Fu, Professor LV Xin and HOU Tong Yu for their considerable comments for manuscript. Thanks to all the fellows who helped me to finish the experiment.

Open Access This article is licensed under a Creative Commons Attribution 4.0 International License, which permits use, sharing, adaptation, distribution and reproduction in any medium or format, as long as you give appropriate credit to the original author(s) and the source, provide a link to the Creative Commons licence, and indicate if changes were made. The images or other third party material in this article are included in the article's Creative Commons licence, unless indicated otherwise in a credit line to the material. If material is not included in the article's Creative Commons licence and your intended use is not permitted by statutory regulation or exceeds the permitted use, you will need to obtain permission directly from the copyright holder. To view a copy of this licence, visit http://creativecommons. org/licenses/by/4.0/.

Authors Contribution All authors contributed to the study conception and design. Material preparation, data collection and analysis were performed by [ Lin Jiao ], [MA Lu lu]. The first draft of the manuscript was written by [LV Xin] an $\mathrm{d}$ all authors commented on previous versions of the manuscript. All authors read and approved the final manuscript. Lin Jiao and Ma Lulu mainly help to obtain experimental data, Hou Tongyu and Zhang Ze mainly modify and guide the content of the manuscript, Zhang Lifu and $\mathrm{L} v$ Xin provide experimental funds and materials, and make suggestions and opinions on the manuscript Yin Caixia and Lin Jiao are the co authors of this manuscript, and Zhang Lifu and LV Xin are the corresponding author. When submitting the manuscript, Yin Caixia will replace Zhang Lifu to submit and check the status of the manuscript.

\section{Appendix}

28

Table 5 Partial vegetation index used in this manuscript

\begin{tabular}{|c|c|c|c|}
\hline $\begin{array}{l}\text { Serial } \\
\text { number }\end{array}$ & $\begin{array}{l}\text { Vegetation } \\
\text { index }\end{array}$ & Definition/Formulas & References \\
\hline 1 & ZMI & $\mathrm{R}_{750} / \mathrm{R}_{710}$ & $\begin{array}{l}\text { Zarco-Tejada } \\
\text { et al. (2001) }\end{array}$ \\
\hline 2 & VOG1 & $\mathrm{R}_{740} / \mathrm{R}_{720}$ & $\begin{array}{l}\text { Vogelmann } \\
\text { et al. (1993) }\end{array}$ \\
\hline 3 & GRVI & $\mathrm{R}_{800} / \mathrm{R}_{550}$ & $\begin{array}{l}\text { Gitelson et al. } \\
(2002)\end{array}$ \\
\hline 4 & RVI & $\mathrm{R}_{800} / \mathrm{R}_{700}$ & $\begin{array}{l}\text { Merzlyak } \\
\text { et al. (2003) }\end{array}$ \\
\hline 5 & & $\mathrm{R}_{787} / \mathrm{R}_{765}$ & $\begin{array}{l}\text { Fava et al. } \\
\text { (2009) }\end{array}$ \\
\hline 6 & $\mathrm{R} / \mathrm{G}$ & $\mathrm{R}_{\text {Red }} / \mathrm{R}_{\text {green }}$ & $\begin{array}{l}\text { Sims et al. } \\
\text { (2002) }\end{array}$ \\
\hline 7 & MACI & $\mathrm{R}_{\mathrm{NIR}} / \mathrm{R}_{\text {green }}$ & $\begin{array}{l}\text { Gitelson et al. } \\
\text { (2001) }\end{array}$ \\
\hline 8 & DVI & $\mathrm{R}_{\mathrm{NIR}}-\mathrm{R}_{\mathrm{Red}}$ & $\begin{array}{l}\text { Jordan et al. } \\
\text { (1969) }\end{array}$ \\
\hline 9 & GMI & $\left(\mathrm{R}_{750} / \mathrm{R}_{550}\right)-1$ & Gitelson et al. \\
\hline 10 & & $\left(\mathrm{R}_{750} / \mathrm{R}_{720}\right)-1$ & (2001) \\
\hline 11 & ARI & $\left(1 / R_{550}\right)-\left(1 / R_{700}\right)$ & $\begin{array}{l}\text { Merzlyak } \\
\text { et al. (2003) }\end{array}$ \\
\hline 12 & NDVI & $\left(\mathrm{R}_{780}-\mathrm{R}_{550}\right) /\left(\mathrm{R}_{780}+\mathrm{R}_{550}\right)$ & $\begin{array}{l}\text { Leprieur et al. } \\
\text { (2000) }\end{array}$ \\
\hline 13 & & $\left(\mathrm{R}_{810}-\mathrm{R}_{560}\right) /\left(\mathrm{R}_{810}+\mathrm{R}_{560}\right)$ & $\begin{array}{l}\text { Aparicio et al. } \\
\text { (2002) }\end{array}$ \\
\hline 14 & IPVI & $\mathrm{R}_{800} /\left(\mathrm{R}_{800}+\mathrm{R}_{670}\right)$ & $\begin{array}{r}\text { Crippen } \\
(1990)\end{array}$ \\
\hline 15 & MTCI & $\left(\mathrm{R}_{754}-\mathrm{R}_{709}\right) /\left(\mathrm{R}_{709}-\mathrm{R}_{681}\right)$ & $\begin{array}{l}\text { Dash et al. } \\
\text { (2004) }\end{array}$ \\
\hline 16 & PRI & $\left(\mathrm{R}_{570}-\mathrm{R}_{531}\right) /\left(\mathrm{R}_{570}+\mathrm{R}_{531}\right)$ & $\begin{array}{l}\text { Gamon et al. } \\
\text { (1997) }\end{array}$ \\
\hline 17 & SIPI & $\left(\mathrm{R}_{800}-\mathrm{R}_{450}\right) /\left(\mathrm{R}_{800}+\mathrm{R}_{450}\right)$ & $\begin{array}{l}\text { Peuelas et al. } \\
\text { (1995) }\end{array}$ \\
\hline 18 & VOG2 & $\left(\mathrm{R}_{734}-\mathrm{R}_{747}\right) /\left(\mathrm{R}_{715}+\mathrm{R}_{726}\right)$ & Zarco-Tejada \\
\hline 19 & VOG3 & $\left(\mathrm{R}_{734}-\mathrm{R}_{747}\right) /\left(\mathrm{R}_{715}+\mathrm{R}_{720}\right)$ & et al. (2001) \\
\hline 20 & mSR705 & $\left(\mathrm{R}_{750}-\mathrm{R}_{445}\right) /\left(\mathrm{R}_{705}+\mathrm{R}_{445}\right)$ & Sims (2002) \\
\hline 21 & NPCI & $\left(\mathrm{R}_{680}-\mathrm{R}_{430}\right)\left(\mathrm{R}_{680}+\mathrm{R}_{430}\right)$ & $\begin{array}{l}\text { Peuelas et al. } \\
\text { (1994) }\end{array}$ \\
\hline 22 & GNDVI & $\left(\mathrm{R}_{801}-\mathrm{R}_{550}\right) /\left(\mathrm{R}_{801}+\mathrm{R}_{550}\right)$ & $\begin{array}{l}\text { Gitelson et al. } \\
(2002)\end{array}$ \\
\hline 23 & RENDVI & $\left(\mathrm{R}_{750}-\mathrm{R}_{705}\right) /\left(\mathrm{R}_{750}+\mathrm{R}_{705}\right)$ & $\begin{array}{l}\text { Gitelson et al. } \\
\text { (1994) }\end{array}$ \\
\hline 24 & mND705 & $\begin{array}{l}\left(\mathrm{R}_{750^{-}}-\mathrm{R}_{705}\right) /\left(\mathrm{R}_{750}+\mathrm{R}_{705^{-}}\right. \\
\left.\quad 2 \mathrm{R}_{445}\right)\end{array}$ & $\begin{array}{l}\text { Sims } \\
\text { et al.(2002) }\end{array}$ \\
\hline 25 & NPQI & $\left(\mathrm{R}_{415}-\mathrm{R}_{435}\right) /\left(\mathrm{R}_{415}+\mathrm{R}_{435}\right)$ & $\begin{array}{l}\text { Barnes et al. } \\
\text { (1992) }\end{array}$ \\
\hline 26 & HDNVI & $\left(\mathrm{R}_{827}-\mathrm{R}_{668}\right) /\left(\mathrm{R}_{827}+\mathrm{R}_{668}\right)$ & $\begin{array}{l}\text { Oppelt et al. } \\
\text { (2004) }\end{array}$ \\
\hline 27 & SAVI & $\begin{array}{l}\text { I. } .5\left(\mathrm{R}_{800^{-}} \mathrm{R}_{670}\right) /\left(\mathrm{R}_{800^{-}}\right. \\
\left.\quad \mathrm{R}_{670}+0.5\right)\end{array}$ & $\begin{array}{l}\text { Rondeaux } \\
\text { et al. (1996) }\end{array}$ \\
\hline 28 & OSAVI & $\begin{array}{c}(1+0.16)\left(\mathrm{R}_{790^{-}} \mathrm{R}_{670}\right) / \\
\left(\mathrm{R}_{790^{-}}-\mathrm{R}_{670}+0.16\right)\end{array}$ & \\
\hline
\end{tabular}

See Table 5 . 
Table 5 (continued)

\begin{tabular}{|c|c|c|c|}
\hline $\begin{array}{l}\text { Serial } \\
\text { number }\end{array}$ & $\begin{array}{l}\text { Vegetation } \\
\text { index }\end{array}$ & Definition/Formulas & References \\
\hline 29 & VAGR & $\begin{array}{l}\left(\mathrm{R}_{560^{-}} \mathrm{R}_{670}\right) /\left(\mathrm{R}_{560}+\mathrm{R}_{670^{-}}\right. \\
\left.\mathrm{R}_{450}\right)\end{array}$ & $\begin{array}{l}\text { Gitelson et al } \\
(2002)\end{array}$ \\
\hline 30 & ARVI & $\begin{array}{l}\left(\mathrm{R}_{800^{-}} \mathrm{R}_{670}\right) /\left(\mathrm{R}_{800}+\mathrm{R}_{670^{-}}\right. \\
\left.\mathrm{R}_{450}\right)\end{array}$ & $\begin{array}{l}\text { Huete et al. } \\
\text { (1994) }\end{array}$ \\
\hline 31 & MCARI & $\begin{array}{l}{\left[\left(\mathrm{R}_{700^{-}} \mathrm{R}_{670}\right)-0.2\left(\mathrm{R}_{700^{-}}\right.\right.} \\
\left.\left.\mathrm{R}_{500}\right)\right]\left(\mathrm{R}_{700} / \mathrm{R}_{670}\right)\end{array}$ & $\begin{array}{l}\text { Daughtry } \\
\text { et al. (2000) }\end{array}$ \\
\hline 32 & TSARI & $\begin{array}{l}3\left[\left(\mathrm{R}_{700^{-}} \mathrm{R}_{670}\right)-0.2\left(\mathrm{R}_{700^{-}}\right.\right. \\
\left.\left.\quad \mathrm{R}_{550}\right)\left(\mathrm{R}_{700} / \mathrm{R}_{670}\right)\right]\end{array}$ & $\begin{array}{l}\text { Haboudane } \\
\text { et al. (2004) }\end{array}$ \\
\hline 33 & VARI red & $\begin{array}{c}\left(\mathrm{R}_{700}-1.7 \mathrm{R}_{670}+0.7 \mathrm{R}_{450}\right) / \\
\left(\mathrm{R}_{700}+2.3 \mathrm{R}_{670^{-}}-1.3 \mathrm{R}_{450}\right)\end{array}$ & $\begin{array}{l}\text { Gitelson et al } \\
\text { (2002) }\end{array}$ \\
\hline 34 & TVI & $\begin{array}{l}60\left(\mathrm{R}_{800}-\mathrm{R}_{550}\right)-100\left(\mathrm{R}_{670^{-}}\right. \\
\left.\mathrm{R}_{550}\right)\end{array}$ & $\begin{array}{l}\text { Broge et al. } \\
(2003)\end{array}$ \\
\hline 35 & MTVI1 & $\begin{array}{l}1.2\left(1.2\left(\mathrm{R}_{800}-\mathrm{R}_{550}\right)-2 .\right. \\
\left.5\left(\mathrm{R}_{670}-\mathrm{R}_{550}\right)\right)\end{array}$ & \\
\hline 36 & TSARI & $\begin{array}{l}3\left[\left(\mathrm{R}_{700}-\mathrm{R}_{670}\right)-0.2\left(\mathrm{R}_{700^{-}}\right.\right. \\
\left.\quad \mathrm{R}_{550}\right)\left(\mathrm{R}_{700} / \mathrm{R}_{670}\right)\end{array}$ & $\begin{array}{l}\text { Haboudane } \\
\text { et al. (2003) }\end{array}$ \\
\hline 37 & BmSR705 & $\begin{array}{l}\left(\mathrm{DR}_{750^{-}} \mathrm{DR}_{445}\right) /\left(\mathrm{DR}_{705^{-}}\right. \\
\left.\mathrm{DR}_{445}\right)\end{array}$ & $\begin{array}{l}\text { Liu et al. } \\
\text { (2011) }\end{array}$ \\
\hline
\end{tabular}

\section{References}

Aparicio, N., Villegas, D., Araus, J. L., Casadesús, J., \& Royo, C. (2002). Relationship between growth traits and spectral vegetation indices in durum wheat. Crop Science, 42(5), 1547-1555.

Barnes, J. D., Balaguer, L., \& Manrique, E. (1992). A reappraisal of the use of DMSO for the extraction and determination of chlorophylls a and b in lichens and higher plants. Environmental and Experimental botany, 32(2), 85-100.

Blackmer, T. M., Schepers, J. S., Gary, E., Varvel, G. E., \& WalterShea, E. A. (1996). Nitrogen deficiency detection using reflected shortwave radiation from irrigated corn canopies. Agronomy Journal, 88(1), 1-5.

Broge N. H., Thomsen A., Andersen P. B. (2003). Stability of selected vegetation indices commonly employed as indicators of crop development-The red edge inflection point (REIP) and the ratio vegetation index (RVI)[C]/Proceedings of the seminar on implementation of precision farming in practical agriculture. 146-149.

Chen, P., Haboudane, D., Tremblay, N., Wang, J., Vigneault, P., \& Li, B. (2010). New spectral indicator access the efficiency of crop nitrogen treatment in corn and wheat. Remote Sensing of environment, 114(9), 1987-1997.

Crippen R. E.(1990). Calculating the vegetation index faster. Remote Sensing of Environment, 34(1):71-73.

Dash, J., \& Curran, P. J. (2004). The MERIS terrestrial chlorophyll index. International Journal of Remote Sensing, 25(23), 5403-5413.

Daughtry, C. S. T., Walthall, C. L., \& Kim, M. S. (2000). Estimating corn leaf chlorophyll concentration from leaf and canopy reflectance. Remote sensing of Environment, 74(2), 229-239.
Fava, F., Colombo, R., Bocchi, S., Meroni, M., Sitzia, M., Fois, N., \& Zucca, C. (2009). Identification of hyperspectral vegetation indices for mediterranean pasture characterization. International Journal of Applied Earth Observation and Geoinformation, 11(4), 233-243.

Feng, L., Fang, H., Zhou, W. J., Wang, M., \& He, Y. (2006). Nitrogen stress measurement of canola based on multi-spectral charged coupled device imaging sensor. Spectroscopy and Spectral Analysis, 26(9), 1749-1752.

Fitzgerald, G., Rodriguez, D., \& O’Leary, G. (2010). Measuring and predicting canopy nitrogen nutrition in wheat using a spectral index-the canopy chlorophyll content index (CCCI). Field Crops Research, 116(3), 318-324.

Follett, R. H., Follett, R. F., \& Halvorson, A. D. (1992). Use of a chlorophyll meter to evaluate the nitrogen status of dry land winter wheat. Communications in Soil Science and Plant Analysis, 23(7-8), 687-697.

Gamon, J. A., Serrano, L., \& Surfus, J. (1997). The photochemical reflectance index: an optical indicator of photosynthetic radiation-use efficiency across species, functional types, and nutrient levels. Oecologia, 112, 492-501.

Gitelson, A. A., Kaufman, Y. J., \& Stark, R. (2002). Novel algorithms for remote estimation of vegetation fraction. Remote sensing of Environment, 80(1), 76-87.

Gitelson, A., \& Merzlyak, M. N. (1994). Quantitative estimation of chlorophyll-a using reflectance spectra: Experiments with autumn chestnut and maple leaves. Journal of Photochemistry and Photobiology B: Biology 22(3), 247-252.

Gitelson, A. A., Merzlyak, M. N., \& Chivkunova, O. B. (2001). Optical properties and nondestructive estimation of anthocyanin content in plant leaves. Photochemistry and photobiology, 74(1), $38-45$.

Haboudane, D., Miller, J. R., \& Pattey, E. (2004). Hyperspectral vegetation indices and novel algorithms for predicting green LAI of crop canopies: Modeling and validation in the context of precision agriculture. Remote sensing of environment, 90(3), $337-352$.

Haboudane, D., Miller, J. R., \& Tremblay, N. (2002). Integrated narrow-band vegetation indices for prediction of crop chlorophyll content for application to precision agriculture. Remote sensing of environment, 81(2-3), 416-426.

Huete, A., Justice, C., \& Liu, H. (1994). Development of vegetation and soil indices for MODIS-EOS. Remote Sensing of environment, 49(3), 224-234.

Inoue, Y., Moran, M. S., \& Horie, T. (1998). Analysis of spectral measurements in paddy field for predicting rice growth and yield based on simple crop simulation model. Plant Production Science, 1, 269-279.

Jia, F. F., Liu, G. S., Liu, D. S., Zhang, Y. Y., Fan, W. G., \& Xing, X. X. (2013). Comparison of different methods for estimating nitrogen concentration in flue-cured tobacco leaves based on hyper spectral reflectance. Field Crops Research, 150, 108-114.

Jia, L. L., Chen, X. P., Zhang, F. S., Andreas, B., \& Volker, R. (2007). Use of digital camera to assess nitrogen status of winter wheat in the northern china plain. Journal of Plant Nutrition, 27(3), $441-450$.

Jordan, C. F. (1969). Derivation of leaf area index from quality of light on the forest floor. Ecology, 50(4), 663-666.

Leprieur, C., Kerr, Y. H., Mastorchio, S., \& Meunier, J. C. (2000). Monitoring vegetation cover across semi-arid regions: Comparison of remote observations from various scales. International Journal of Remote Sensing, 21, 281-300.

Liu, L., Shen, R. P., \& Ding, G. X. (2011). Estimation of soil organic matter content based on hyperspectral data. Spectroscopy and spectral analysis, 31(3), 762-766. 
Luciano, S., Richard, F., John, S., Viacheslav, A., Donald, R., David, M., \& Glen, S. (2011). Water and nitrogen effects on active canopy sensor vegetation indices. Agronomy Journal, 103(6), 1815.

Malavolta, E., Nogueira, N. G. L., Heinrichs, R., Higashi, E. N., Rodríguez, V., Guerra, E., Oliveira, S. C., Cabral, C., \& Cabral, P. (2004). Evaluation of nutritional status of the cotton plant with respect to nitrogen. Communications in Soil Science and Plant Analysis, 35, 1007-1020.

Merzlyak, M. N., Gitelson, A. A., Chivkunova, O. B., Solovchenko, A. E., \& Pogosyan, S. I. (2003). Application of Reflectance Spectroscopy for Analysis of Higher Plant Pigments. Russian Journal of Plant Physiology, 50(5), 704-710.

Merzlyak, M. N., Solovchenko, A. E., \& Gitelson, A. A. (2003). Reflectance spectral features and non-destructive estimation of chlorophyll, carotenoid and anthocyanin content in apple fruit. Postharvest Biology and Technology, 27(2), 197-211.

Nguyen, H. T., Kim, J. H., Nguyen, A. T., Lan, T. N., Jin, C. S., \& Lee, B. W. (2006). Using canopy reflectance and partial least squares regression to calculate within-field statistical variation in crop growth and nitrogen status of rice. Precision Agriculture, 7(4), 249-264.

Ollinger, S. V., Richardson, A. D., Martin, M. E., Hollinger, D. Y., Frolking, S. E., Reich, P. B., PlourdeL, C., Katul, G. G., Munger, J. W., Oren, R., Smith, M. L., Paw, U. K. T., Bolstad, P. V., Cook, B. D., Day, M. C., Martin, T. A., Monson, R. K., \& Schmid, H. P. (2008). Canopy nitrogen, carbon assimilation, and albedo in temperate and boreal forests: Functional relations and potential climate feedbacks. Proceedings of the National Academy of Sciences of the United States of America, 105(49), 19336-19341.

Oppelt, N., \& Mauser, W. (2004). Hyperspectral monitoring of physiological parameters of wheat during a vegetation period using AVIS data. International Journal of Remote Sensing, 25(1), 145-159.

Peng, S., Garcia, F. V., Laza, R. C., Sanico, A. L., Visperas, R. M., \& Cassman, K. G. (1996). Increased N-use efficiency using a chlorophyll meter on high-yielding irrigated rice. Field Crops Research, 47(2), 243-252.

Penuelas, J., Baret, F., \& Filella, I. (1995). Semiempirical indexes to assess carotenoids chlorophyll-a ratio from leaf spectral reflectance. Photosynthetica, 31(2), 221-230.

Peuelas, J., Gamon, J. A., Fredeen, A. L., Merino, J., \& Field, C. B. (1994). Reflectance indices associated with physiological changes in nitrogen- and water-limited sunflower leaves. Remote Sensing of Environment, 48(2), 135-146.

Read, J. J., Reddy, K. R., \& Jenkins, J. N. (2005). Yield and fiber quality of upland cotton as influenced by nitrogen and potassium nutrition. European Journal of Agronomy, 24(3), 282-290.

Roger, N. C., \& Ted, L. R. (1984). Reflectance spectroscopy: Quantitative analysis techniques for remote sensing applications. Journal of Geophysical Research, 89(B7), 6329-6340.

Rondeaux, G., Steven, M., \& Baret, F. (1996). Optimization of soiladjusted vegetation indices. Remote sensing of environment, 55(2), 95-107.

Rorie, R. L., Purcell, L. C., Mozaffari, M., Karcher, D. E., \& Longer, D. E. (2011). Association of "greenness" in corn with yield and leaf nitrogen concentration. Agronomy Journal, 103(2), 529-535.

Russell, A. E., Laird, D. A., \& Mallarino, A. P. (2006). Nitrogen fertilization and cropping system impacts on soil quality in midwestern mollisols. Soil science Society of Am Erica Journal, 70(1), 249-255.

Sims, D. A., \& Gamon, J. A. (2002). Relationships between leaf pigment content and spectral reflectance across a wide range of species, leaf structures and developmental stages. Remote Sensing of Environment, 81(2-3), 337-354.

Sims, D. A., \& Gamon, J. A. (2002a). Relationships between leaf pigment content and spectral reflectance across a wide range of species, leaf structures and developmental stages. Remote sensing of environment, 81(2-3), 337-354.

Stone, M. L., Solie, J. B., Raun, W. R., Whitney, R. W., Taylor, S. L., \& Ringer, J. D. (1996). Use of spectral radiance for correcting in-season fertilizer nitrogen deficiencies in winter wheat. Transactions of the Asae, 39(5), 1623-1631.

Vogelmann, J. E., Rock, B. N., \& Moss, D. M. (1993). Red edge spectral measurements from sugar maple leaves. REMOTE SENSING, 14(8), 1563-1575.

Wang, R. C., Chen, M. Z., \& Jiang, H. X. (1993). Studies on the agronomic mechanism of rice yield estimation by remote sensing. Journal of Zhejiang Agricultural University, S1, 9-16.

Wang, S. H., Zhu, Y., Jiang, H. D., \& Cao, W. X. (2006). Positional differences in nitrogen and sugar concentrations of upper leaves relate to plant $\mathrm{N}$ status in rice under different $\mathrm{N}$ rates. Field Crops Research, 96(2), 224-234.

Watt, M. S., Clinton, P. W., Whitehead, D., Richardson, B., Mason, E. G., \& Leckie, A. C. (2003). Above-ground biomass accumulation and nitrogen fixation of broom (Cytisus scoparius L.) growing with juvenile pinus radiata on a dryland site. Forest Ecology and Management, 184(1-3), 93-104.

Xue, L. H., Cao, W. X., Luo, W. H., Dai, T. B., \& Zhu, Y. (2004). Monitoring leaf nitrogen status in rice with canopy spectral reflectance. Agronomy Journal, 96(1), 135-142.

Zarco-Tejada, P. J., Miller, J. R., \& Noland, T. L. (2001a). Scaling-up and model inversion methods with narrow band optical indices for chlorophyll content estimation in closed forest canopies with hyperspectral data. IEEE Transactions on Geoscience and Remote Sensing, 39(7), 1491-1507.

Zarco-Tejada, P. J., Miller, J. R., Noland, T. L., Mohammed, G. H., \& Sampson, P. H. (2001). Scaling-up and model inversion methods with narrowband optical indices for chlorophyll content estimation in closed forest canopies with hyperspectral data. IEEE Transactions on Geoscience and Remote Sensing, 39(7), 1491-1507.

Zhang, F. S., \& Ma, W. Q. (2000). The relationship between fertilizer input level and nutrient use efficiency. Soil and Environment Sciences, 9(2), 154-157.

Zhang, L. P. (2014). Advance and future challenges in hyperspectral target detection. Geometrics and Information Science of Wuhan University, 39(12), 1387-1394.

Publisher's Note Springer Nature remains neutral with regard to jurisdictional claims in published maps and institutional affiliations. 